\title{
KARAKTERISTIK BATUBARA DAN PENGARUHNYA TERHADAP PROSES PENCAIRAN
}

\author{
Harli Talla"), Hendra Amijaya, Agung Harijoko, dan Miftahul Huda \\ Jurusan Teknik Geologi, Fakultas Teknik, Universitas Gadjah Mada \\ Jl. Grafika No. 2 Kampus UGM Yogyakarta 55281, Telp. 0274-513668, Fax: 0274-513668 \\ ${ }^{*}$ Penulis korespondensi: harli.talla@yahoo.com
}

\begin{abstract}
CHARACTERISTIC OF COAL AND ITS EFFECT ON LIQUEFACTION PROCESS. This research was conducted to study the influence of coal characteristic to liquefaction by using catalytic hydrogenation method. Coal sample used are Sorong coal which has lignite coal rank and Mulia coal with rank sub bituminous. Liquefaction process is conducted in an autoclave with 5 litre capacities, antrasen is used as solvent and iron ore as catalyst. Temperature variation is $375^{\circ} \mathrm{C}, 400^{\circ} \mathrm{C}, 425^{\circ} \mathrm{C}$, $450^{\circ} \mathrm{C}$, whereas hydrogen blank-off pressure is specified at 100 bars. Results show that Coal characteristic has a significant influence to liquefaction. The highest conversion of Sorong coal is $89.94 \%$ at temperature of $400^{\circ} \mathrm{C}$ and Mulia coal highest conversion is $87.28 \%$ at temperature of $450^{\circ} \mathrm{C}$.
\end{abstract}

Keywords: catalytic hydrogenation method; coal characteristic; Mulia coal; Sorong coal

\begin{abstract}
Abstrak
Tujuan penelitian ini adalah mempelajari pengaruh karakteristik batubara terhadap proses pencairan dengan menggunakan metoda hidrogenasi katalitik. Sampel batubara yang digunakan adalah batubara Sorong dengan peringkat lignit dan batubara Mulia dengan peringkat sub bituminus. Proses pencairan dilakukan dalam sebuah otoklaf yang berkapasitas 5 liter dengan menggunakan pelarut antrasen dan katalis bijih besi. Kisaran suhu pencairan adalah $375^{\circ} \mathrm{C}, 400^{\circ} \mathrm{C}, 425^{\circ} \mathrm{C}$, dan $450^{\circ} \mathrm{C}$, sementara tekanan awal hidrogen ditetapkan 100 bar. Hasil yang diperoleh menunjukan bahwa karakteristik batubara memiliki pengaruh yang signifikan terhadap pencairan. Konversi tertinggi batubara Sorong adalah $89,94 \%$ pada suhu $400^{\circ} \mathrm{C}$, sementara untuk batubara Mulia sebesar 87,28\% pada suhu $450^{\circ} \mathrm{C}$.
\end{abstract}

Kata kunci: metode hidrogenasi katalitik; karakteristik batubara; batubara Mulia;batubara Sorong

\section{PENDAHULUAN}

Kebutuhan energi Indonesia terus meningkat dari tahun ke tahun. Tahun 2009 konsumsi energi nasional sebesar 865,4 juta SBM dan mengalami peningkatan rata-rata 2,2\% per tahun (BPPT, 2009). Kondisi ini mendorong pemerintah agar lebih kreatif dalam mengelola dan memanfaatkan sumber energi yang tersedia secara lebih bijaksana. Melirik sumber daya batubara Indonesia memang cukup besar yang mencapai 104,76 miliar ton. Batubara merupakan salah satu energi utama di Indonesia yang dalam pemanfaatannya dapat menjadi energi alternatif yang menjanjikan dengan cara dikonversi ke bentuk cair.

Secara sederhana proses pencairan batubara adalah proses konversi batubara padat menjadi suatu produk cair, pada suhu dan tekanan hidrogen yang cukup tinggi dengan bantuan katalis dan media pelarut. Pencairan batubara dapat dilakukan dengan dua cara, yaitu pencairan tidak langsung (Indirec Liquefaction) dan pencairan langsung (Direc Liquefaction) (Kleinpeter, 1983; Dong Shi, 2008).

Banyak faktor yang mempengaruhi proses pencairan batubara baik yang berhubungan dengan karakteristik batubara itu sendiri ataupun kondisis operasional pencairan yang diterapkan. Karakteristik batubara seperti kandungan maseral batubara memiliki pengaruh yang cukup signifikan pada proses pencairan. Maseral vitrinit yang terdapat dalam batubara peringkat rendah dapat dengan mudah terhidrogenasi dan tercairkan, sedangkan batubara peringkat tinggi dalam proses pencairan memerlukan energi yang lebih besar. Menurut Tsai (1982) maseral eksinit (liptinit) lebih cocok untuk proses pencairan, sebab maseral eksinit yang terdapat dalam batubara peringkat rendah mempunyai kandungan hidrogen yang tinggi. Sedangkan, inertinit yang terdapat dalam 
semua peringkat batubara tidak cocok untuk proses pencairan karena kandungan hidrogennya rendah.

Batubara peringkat rendah pada umumnya tersusun dari kelompok-kelompok aromatik kecil yang mengandung banyak kelompok lintas hubungan serta fungsional yang sangat reaktif dalam menjalani pemutusan ikatan secara cepat dan luas selama proses pencairan berlangsung (Barsky dkk., 2009). Menurut Marco dkk. (1990) yang melakukan pencairan dengan variabel peringkat batubara, menyimpulkan bahwa batubara peringkat rendah menghasilkan produk cair lebih tinggi dari pada batubara peringkat tinggi.

Penelitian ini bertujuan untuk mengkaji karakteristik batubara Indonesia dengan peringkat yang berbeda untuk melihat pengaruh karakteristik batubara terhadap kenerja proses pencairan.

\section{METODE PENELITIAN \\ Bahan}

Percobaan ini menggunakan batubara yang diambil dari daerah Sorong Papua Barat yang berperingkat lignit dan batubara Mulia dari PKP2B PT Bumi Resources Kalimantan Selatan dengan peringkat sub-bituminus. Karakteristik kedua batubara tersebut diperlihatkan pada Tabel 1. Pelarut yang digunakan untuk pencairan ini adalah antrasen yang berasal dari hasil pencairan batubara Banko, dengan komposisi karbon $87,13 \%$ berat, hidrogen $9,43 \%$ berat dan rasio $\mathrm{H} / \mathrm{C}$ mencapai 1,3 .

Penelitian ini menggunakan katalis bijih besi yang diperoleh dari PT.Yiwan Kalimantan Selatan. Pemilihan bijih besi sebagai katalis karena memiliki kandungan besi (Fe), hasil analisis kimia menunjukan bijih besi terdiri dari $\mathrm{Fe} 53,6 \%$ dan $\mathrm{Fe}_{2} \mathrm{O}_{3}$ sebesar $76,6 \%$. Sulfur yang digunakan adalah sulfur bubuk dan dicampur dengan katalis bijih besi. Penggunaan katalis bijih besi dan sulfur akan tertransformasi menjadi pirhotit $\left(\mathrm{Fe}_{1-\mathrm{x}} \mathrm{S}\right)$ pada kondisi pencairan batubara dan mempercepat konversi batubara menjadi produk cair.

\section{Prosedur Pencairan dan Pemisahan Produk}

Pencairan batubara dilangsungkan pada reaktor otoklaf volume 5 liter (lihat Gambar 1). Perbandingan antara batubara dan pelarut yang digunakan pada percobaan ini adalah 2/1 atau 600 gram pelarut dan 400 gram batubara. Sampel batubara yang digunakan digerus dengan ukuran 200 mesh dan dikeringkan dalam oven dengan suhu $80-100^{\circ} \mathrm{C}$, selama 120 menit untuk mengurangi kadar air.

Umpan yang terdiri dari batubara, pelarut, katalis dan sulfur dicampur dan dimasukkan ke dalam otoklaf, lalu dilakukan deaerasi dengan nitrogen dan hidrogen tujuannya untuk membersikan sisa gas yang ada dalam otoklaf. Otoklaf lalu diisi gas hidrogen dengan tekanan awal 100 bar dan dipanaskan.

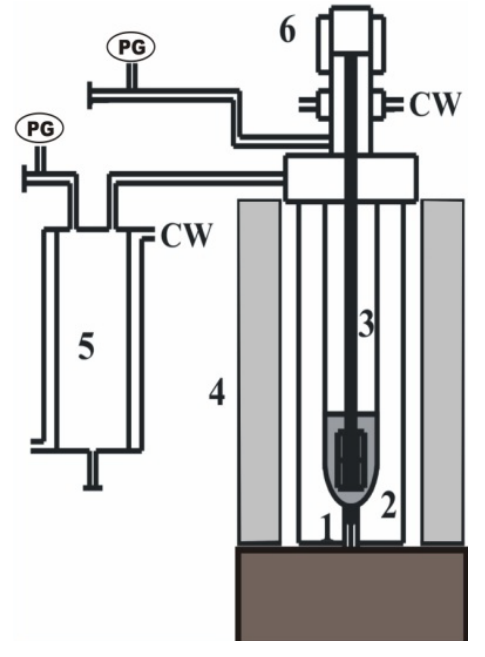

Keterangan :

1. Termokopel

2. Tabung reaktor (Autoclave)

3. Pengaduk

4. IR Furnace

5. Buffle Tank

6. Motor

Gambar 1. Otoklaf kapasitas 5 liter

Proses pemanasan berlangsung sesuai dengan suhu yang telah ditentukan. Selanjutnya, produk batubara cair yang dihasilkan dikeluarkan dari otoklaf dan disaring dengan saringan kawat ukuran 250 mesh. Ampas hasil penyaringan kemudian diekstraksi dengan menggunakan toluen untuk membersihkan minyak dan air yang masih menyatu dengan ampas, selanjutnya dapat dihitung ampas total.

Hasil penelitian menunjukan bahwa perolehan batubara cair didapat dengan menghitung selisih antara minyak dengan ampas. Satu kilogram batubara Sorong menghasilkan 812,975 gram batubara cair yang jika dikonversi ke liter sebesar 0,961 liter, sehingga satu ton batubara Sorong akan menghasilkan 961,59 liter atau 6,048 barrel (minyak dan air).

\section{HASIL DAN PEMBAHASAN \\ Karakteristik batubara}

Hasil analisa proksimat dan ultimat menunjukan bahwa batubara Sorong termasuk dalam peringkat lignit sedangkan batubara Mulia digolongkan ke dalam peringkat sub bituminous. Karakteristik kedua jenis batubara tersebut dapat dilihat pada Tabel 1.

Hasil analisa petrografi batubara Sorong dan batubara Mulia pada Tabel 2, memperlihatkan adanya perbedaan yang berarti dari presentase maseral penyusun kedua batubara tersebut, dimana batubara Sorong memiliki lebih banyak liptinit daripada batubara Mulia.

Reflektan vitrinit rata-rata batubara Sorong sebesar 0,40\% dan batubara Mulia sebesar 0,44\%. Perbedaan Reflektan vitrinit ini memperlihatkan kembali bahwa batubara Sorong berperingkat lignit 
dan batubara Mulia termasuk dalam peringkat subbituminus.

Tabel 1. Analisis proksimat dan analisa ultimat batubara Sorong dan batubara Mulia

\begin{tabular}{lccc}
\hline \multirow{2}{*}{$\begin{array}{c}\text { Parameter } \\
\text { analisis }\end{array}$} & \multicolumn{2}{c}{ Batubara } & \multirow{2}{*}{ Unit } \\
\cline { 2 - 3 } & Sorong & Mulia & \\
\hline - Proksimat: & & & \\
\hline Kandungan air & 32,03 & 26,05 & $\% \mathrm{adb}$ \\
Kandungan abu & 4,94 & 2,17 & $\% \mathrm{adb}$ \\
Zat terbang & 32,80 & 30,44 & $\% \mathrm{adb}$ \\
Karbon tetap & 30,23 & 35,34 & $\% \mathrm{adb}$ \\
Nilai kalor & 4090 & 4669 & $\mathrm{kal} / \mathrm{g}$ \\
\hline - Ultimat: & & & \\
\hline Karbon & 52,34 & 52,67 & $\% \mathrm{adb}$ \\
Hidrogen & 7,18 & 5,23 & $\% \mathrm{adb}$ \\
Nitrogen & 0,64 & 0,37 & $\% \mathrm{adb}$ \\
Total sulfur & 0,89 & 0,17 & $\% \mathrm{adb}$ \\
Oksigen & 37,21 & 24,17 & $\% \mathrm{adb}$ \\
Rasio H/C & 1,6 & 1,1 & $\mathrm{~mol}$ \\
\hline
\end{tabular}

Tabel 2. Hasil analisa maseral batubara Sorong dan batubara Mulia

\begin{tabular}{lccc}
\hline \multicolumn{1}{c}{ Analisa } & \multicolumn{2}{c}{ Batubara } & \multirow{2}{*}{ Unit } \\
\cline { 2 - 3 } \multicolumn{1}{c}{ Maseral } & Sorong & Mulia & \\
\hline Vitrinit & 77,8 & 72,7 & $\%$ vol \\
Liptinit/eksinit & 3,8 & 1,5 & $\%$ vol \\
Inertinit & 11,8 & 14,6 & $\%$ vol \\
\hline Mineral metter: & & & \\
\hline Pirit & 5,0 & 1,7 & $\%$ vol \\
Clay & 1,6 & 9,5 & $\%$ vol \\
\hline Rev. Vitrinit: & & & \\
\hline Rv rata - rata & 0,40 & 0,44 & $\% \mathrm{Rv}$ \\
\hline
\end{tabular}

Maseral-maseral yang terkandung dalam batubara Sorong terdiri atas dotrovitinit, semifusinit dan resinit yang saling mengisi (Gambar 2a). Kenampakan mineral pirit juga hadir dalam batubara Sorong yang tersisip di antara dotrovitinit. Sedangkan maseral utama yang terkandung dalam batubara Mulia antara lain: maseral suberinit, resinit yang terlihat jelas pada Gambar 3a, dan Gambar 3b nampak kehadiran maseral sklerotinit yang bergabung dengan detrovitrinit.
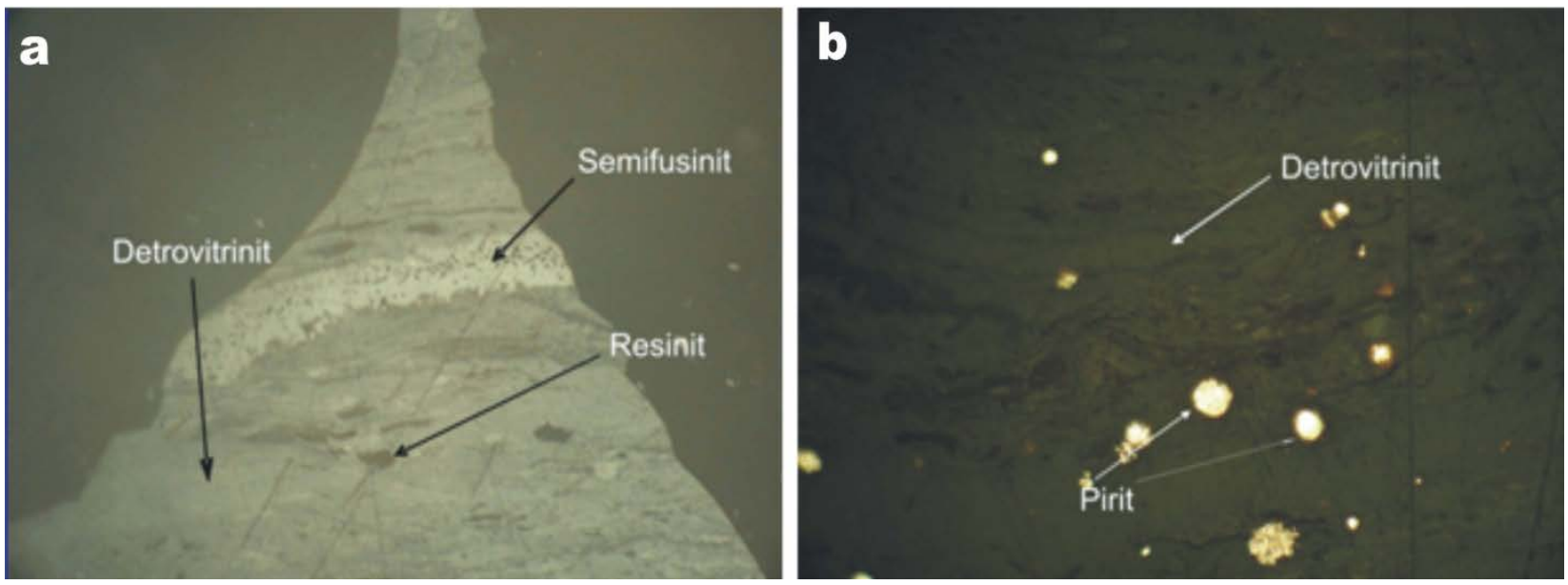

Gambar 2. Batubara Sorong dalam sinar reflektan pembesaran 200 X. a) nampak maseral detrovitrinit, semifusinit dan resinit. b) Detrovitrinit bergabung dengan pirit
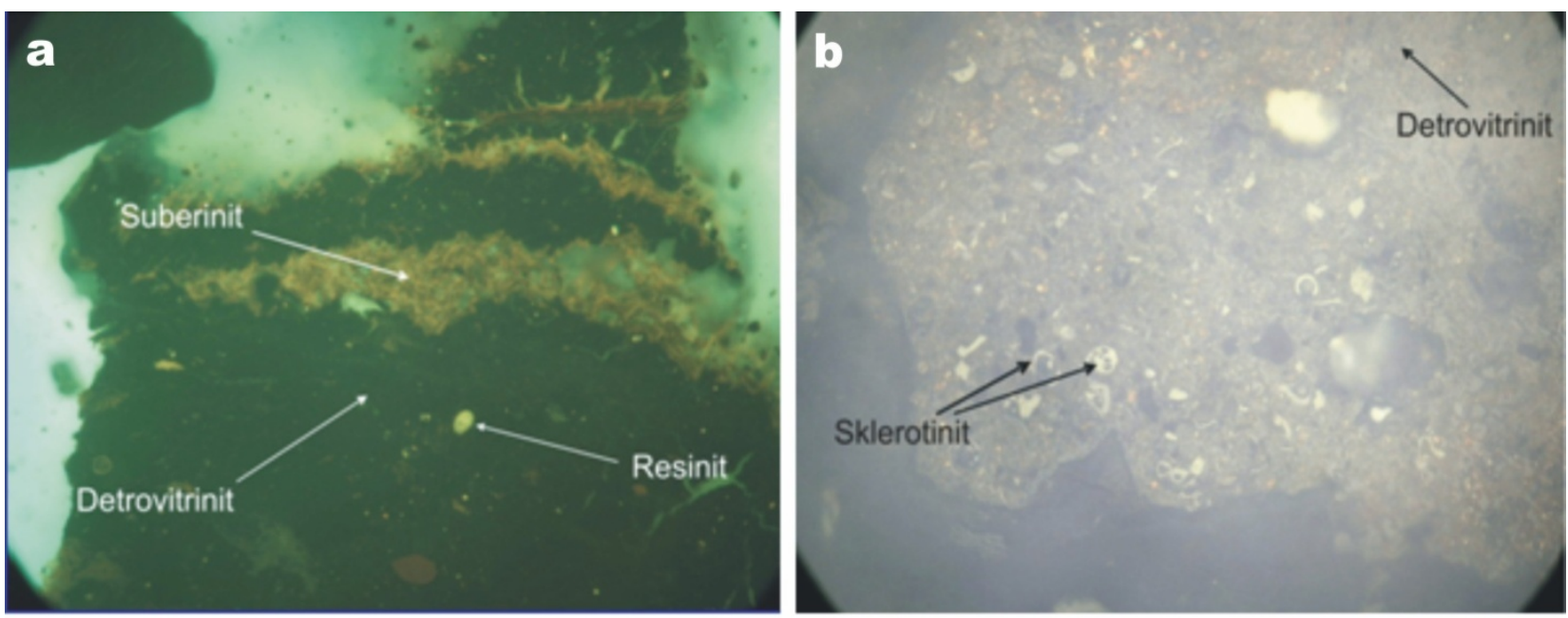

Gambar 3. Batubara Mulia dalam sinar reflektan pembesaran 200 X. a) Maseral suberinit dan resinit bergabung dengan detrovitrinit. b) Maseral detrovitrinit dan sklerotinit 


\section{Pencairan Batubara}

Hasil pengujian pencairan batubara Sorong konversi tertinggi sebesar 89,94\% dengan ampas hanya 40,21 gram pada suhu $400^{\circ} \mathrm{C}$ dan batubara Mulia konversi tertinggi sebesar $87,28 \%$ dengan ampas 50,87 gram pada suhu $450^{\circ} \mathrm{C}$. Konversi terendah batubara Sorong dan batubara Mulia hanya sebesar 53,15\% untuk batubara Sorong dan batubara Mulia 50,85 \% (lihat Tabel 3).

Tabel 3. Hasil pencairan batubara Sorong dan batubara Mulia

\begin{tabular}{cccc}
\hline Sampel & $\begin{array}{c}\text { Suhu } \\
\left({ }^{\circ} \mathrm{C}\right)\end{array}$ & $\begin{array}{c}\text { Total ampas } \\
(\mathrm{gr})\end{array}$ & $\begin{array}{c}\text { Konversi } \\
(\%)\end{array}$ \\
\cline { 2 - 4 } Batubara & 375 & 187,40 & 53,15 \\
Sorong & 400 & 40,21 & 89,94 \\
& 425 & 52,96 & 86,76 \\
& 450 & 82,96 & 79,26 \\
\hline \multirow{3}{*}{ Batubara } & 375 & 196,59 & 50,85 \\
Mulia & 400 & 77,16 & 80,71 \\
& 425 & 71,93 & 82,01 \\
& 450 & 50,87 & 87,28 \\
\hline
\end{tabular}

\section{Pengaruh Karakteristik terhadap Konversi Batubara}

Hasil pencairan batubara Sorong dan batubara Mulia menunjukan adanya peningkatan konversi yang cukup signifikan. Batubara Sorong konversi maksimal sebesar 89,94\% dan batubara Mulia konversi maksimal 87,28\% (Tabel 3). Keberhasilan proses pencairan dipengaruhi oleh karakteristik kedua batubara.

Pertama, kandungan hidrogen. Batubara Sorong dan batubara Mulia merupakan batubara peringkat rendah yang memiliki kandungan hidrogen yang tinggi antara 5,23-7,18\% (lihat Tabel 1).

Kandungan hidrogen yang tinggi akan mempengaruhi rasio hidrogen per karbon menjadi semakin tinggi, seperti yang ditunjukan pada Tabel 1, batubara Sorong yang kaya hidrogen mempunyai rasio $\mathrm{H} / \mathrm{C}$ sangat tinggi mencapai 1,6 dan rasio $\mathrm{H} / \mathrm{C}$ batubara Mulia hanya 1,1. Pengaruhnya terhadap konversi terlihat pada Gambar 4 perbandingan konversi batubara Sorong dan batubara Mulia, grafik ini menggambarkan bahwa batubara Sorong dengan rasio $\mathrm{H} / \mathrm{C}$ tinggi menghasilkan konversi cair tinggi mencapai 89,94\%. Hal ini karena rasio H/C batubara yang semakin tinggi maka akan semakin reaktif atau mudah terkonversi pada suhu rendah karena rasio $\mathrm{H} /$ Cnya mendekati rasio $\mathrm{H} / \mathrm{C}$ minyak. Menurut Wasaka dkk. (2002) menyebutkan bahwa ada korelasi linier antara hasil konversi dengan rasio $\mathrm{H} / \mathrm{C}$, yakni semakin tinggi rasio $\mathrm{H} / \mathrm{C}$ semakin mudah cair.

Kedua, kandungan zat terbang (Volatile matter). Zat terbang dari kedua batubara ini juga memberikan pengaruh terhadap peningkatan konversi, kandungan zat terbang batubara Sorong 32,80\% dan batubara Mulia 30,44\% (lihat Tabel 1).

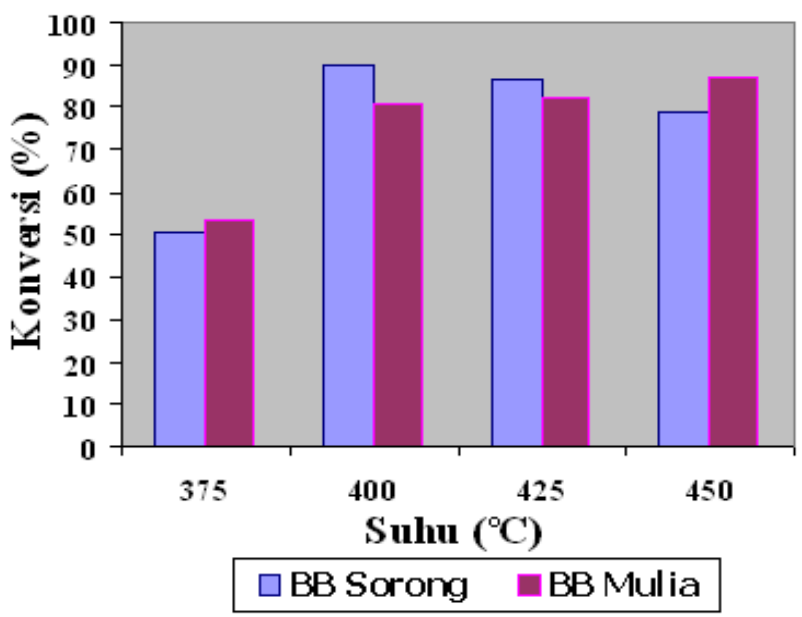

Gambar 4. Perbandingan konversi batubara Sorong dan batubara Mulia

Kandungan zat terbang yang tinggi menunjukan bahwa kedua batubara ini di dominasi oleh struktur alifatik dan gugus fungsional eter $(-\mathrm{O}-)$ yang lemah dan mudah putus ketika dipanaskan pada suhu tinggi. Hasil penelitian ini juga sejalan dengan hasil penelitian Karaca dkk. (2006) yang berkesimpulan bahwa batubara peringkat rendah mengkasilkan konversi yang lebih tinggi dalam pencairan karena tersusun oleh struktur-struktur lemah yang mudah putus dalam panas dan tekanan yang tinggi.

Ketiga, pengaruh komposisi maseral (Maceral composition). Batubara Sorong memiliki maseral reaktif seperti vitrinit sebesar $77,8 \%$ vol dan liptinit 3,8\% vol (lihat Tabel 2). Maseral vitrinit dan liptinit adalah grup maseral yang mudah dicairkan dan menghasilkan konversi tinggi karena rasio $\mathrm{H} / \mathrm{C}$ maseral vitrinit dan liptinit mendekati rasio $\mathrm{H} / \mathrm{C}$ minyak. Kesimpulan mengenai pengaruh komposisi meseral memiliki kesamaan dengan hasil penelitian Tsai (1982) bahwa batubara dengan maseral liptinit dan vitrinit yang tinggi akan mudah dicairkan pada kondisi normal.

Rendahnya hasil konversi batubara Mulia dibandingkan batubara Sorong karena tingginya kandungan lempung (Clay) dalam batubara Mulia yang mencapai 9,5\% vol (Tabel 2). Keberadaan lempung dalam batubara tidak akan habis diakhir reaksi tetapi akan membentuk ampas sehingga mengurangi hasil konversi. Selain itu, kandungan maseral inertinit batubara Mulia cukup tinggi, dimana maseral inertinit yang terkandung dalam batubara peringkat rendah akan sukar dicairkan pada suhu normal atau membutuhkan suhu yang lebih tinggi.

Masalah pada pencairan batubara peringkat rendah adalah kandungan air yang tinggi. Batubara Sorong memiliki kandungan air tinggi sebesar 32,03\%. Kandungan air akan mempengaruhi proses pencairan dimana tekanan dalam otoklaf menjadi lebih besar karena adanya uap air dan hasil konversi pencairan akan banyak air. Namun kondisi ini dapat diatasi dengan pengeringan/pengovenan batubara sebelum umpan batubara dimasukan ke dalam otoklaf. 


\section{KESIMPULAN}

Berdasarkan hasil pengujian pencairan yang dilakukan tehadap batubara Sorong dan batubara Mulia yang memiliki karakteristik berbeda, maka dapat disimpulkan bahwa batubara Sorong merupakan batubara berperingkat lignit dengan konversi maksimal sebesar $89,94 \%$ pada suhu $400^{\circ} \mathrm{C}$. Batubara Mulia dengan peringkat subbituminus, konversi maksimal sebesar $87,28 \%$ pada suhu $450^{\circ} \mathrm{C}$. Karakteristik batubara sangat berpengaruh terhadap proses pencairan. Batubara peringkat rendah mudah dicairkan karena rasio $\mathrm{H} / \mathrm{C}$ lebih tinggi dan strukturnya tersusun oleh ikatan-ikatan lemah yang mudah putus serta mengandung lebih banyak grup maseral yang mudah cair seperti vitrinit dan liptinit.

\section{UCAPAN TERIMAKASIH}

Penulis ingin mengucapkan terima kasih kepada Ir. Hermanu selaku Kepala Laboratorium Pencairan Batubara tekMIRA atas segala fasilitas dan Kepala Dinas Pendidikan Provinsi Papua yang talah menfasilitasi pengambilan sampel batubara.

\section{DAFTAR PUSTAKA}

Barsky, V., Vlasov, G., and Rudnitsky, A., (2009), Composition and Structure of Coal Organic Mass, Analytical Review Chemistry \& Chemical Technology, Vol. 3, No. 4, pp. 315-320.
BPPT, (2009), Outlook Energi Indonesia 2009, Teknologi Energi untuk Mendukung Keamanan Pasokan Energi, Jakarta.

Dong Shi, S., LiWen, B., Wang, Y., Zhi, G., and Jian, L.K., (2008), Study on the Mechanism of Coal Liquefaction Reaction and a New Process Concept, Journal of Coal science and Engineering, Vol. 14. No. 1, pp. 119-124.

Karaca, H., (2006), Effect of Coal Liquefaction Conditions on the Composition of the Product Oil, Energy Sources, 28, pp.1483-1492

Kleinpeter, J.A., (1983), Coal Liquefaction Products, John Wiley \& Sons inc., New York, pp. 1-413.

Marco, I. and Chomon, M.J., (1990), Relationship Between Liquefaction Yields and Characteristics of Different Rank Coals, Elsevier Scientific Publishing No. 24. Chemical Engineering Depertement Bilbao, Spain, pp. 127-133.

Tsai, S.C., (1982), Fundamentals of Coal Beneficiation and Utilization, Coal Science and Technology 2, Elsevier Scientific Publishing No. 375. New York, pp. 151-159

Wasaka, S., Ibaragi, S., Hashimoto, T., Tsukui, Y., Katsuyama, T., and Shidong, S., (2002), Study on Coal Liquefaction Characteristics of Chinese Coals, Fuel, 81, pp.1551-1557. 